\title{
$2-2021$
}

\section{Assessment of the Diagnostic Accuracy of Core Needle Biopsies in the Diagnosis of Lymphoma}

\author{
Austin Redilla \\ Thomas Jefferson University, austin.redilla@students.jefferson.edu \\ George Ye \\ Catherine Tucker, MD \\ Thomas Jefferson University, catherine.tucker@jefferson.edu \\ Christopher Gardner \\ Thomas Jefferson University, christopher.gardner@students.jefferson.edu \\ Guldeep Uppal, MD \\ Thomas Jefferson University, Guldeep.Uppal@jefferson.edu \\ Follow this and additional works at: https://jdc.jefferson.edu/si_ctr_2023_phase1

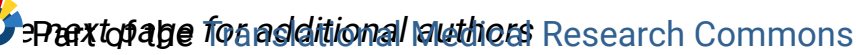 \\ Let us know how access to this document benefits you
}

\section{Recommended Citation}

Redilla, Austin; Ye, George; Tucker, MD, Catherine; Gardner, Christopher; Uppal, MD, Guldeep; and Binder, MD, Adam F., "Assessment of the Diagnostic Accuracy of Core Needle Biopsies in the Diagnosis of Lymphoma" (2021). Phase 1. Paper 99.

https://jdc.jefferson.edu/si_ctr_2023_phase1/99

This Article is brought to you for free and open access by the Jefferson Digital Commons. The Jefferson Digital Commons is a service of Thomas Jefferson University's Center for Teaching and Learning (CTL). The Commons is a showcase for Jefferson books and journals, peer-reviewed scholarly publications, unique historical collections from the University archives, and teaching tools. The Jefferson Digital Commons allows researchers and interested readers anywhere in the world to learn about and keep up to date with Jefferson scholarship. This article has been accepted for inclusion in Phase 1 by an authorized administrator of the Jefferson Digital Commons. For more information, please contact: JeffersonDigitalCommons@jefferson.edu. 


\section{Authors}

Austin Redilla; George Ye; Catherine Tucker, MD; Christopher Gardner; Guldeep Uppal, MD; and Adam F. Binder, MD 


\section{Sidney Kimmel}

Medical College.

at Thomas Jefferson University

\section{Assessment of the Diagnostic Accuracy of Core}

Needle Biopsies in the Diagnosis of Lymphoma

Austin Redilla, Xiangyun Ye, Catherine Tucker, MD , Christopher Gardner, Guldeep Uppal, MD and Adam F. Binder, MD*

$\left.{ }^{*}\right)$ indicates primary project advisor

$\left.{ }^{(\star *}\right)$ indicates another student who is declaring the same project as primary for SI 


\section{Introduction \& Objectives}

- Excisional biopsy is the gold standard in diagnosis of suspected lymphomas

- Core Needle Biopsy (CNB) offers an alternative

- Less expensive

- Non-invasive

- Fewer procedural risks

- We want to evaluate the accuracy of CNB at TJUH to provide guidance for initial workup of suspected lymphoma 
Sidney Kimmel

Medical College.

at Thomas Jefferson University

\section{Objectives \\ \& Hypothesis}

- Research Question

- What is the diagnostic accuracy of excisional and core needle biopsies at Thomas Jefferson University Hospital?

- Hypothesis

- We expect CNB will be similar in diagnostic ability to excisional biopsy in the diagnosis of lymphomas. 


\section{Approach \& Results}

- Medical chart review of all suspected new diagnosis of

lymphomas at Thomas Jefferson University

- January 1st, 2016 to December 31st, 2019

- All CNB and Excisional biopsies in these patients will be reviewed

- Cases from outside hospitals referred to Jefferson were excluded

- Type of biopsy

- Site

- Additional CNB or excisional biopsies, if applicable

- Final pathologic diagnosis

- Ancillary studies used (immunohistochemistry, FISH, etc)

- Data obtained from Thomas Jefferson University pathology labs

- Adequacy and diagnostic odds ratio will be calculated for CNB and excisional biopsies 


\section{Approach and Results}

- 457 cases reviewed; 339 excisional and 118 CNB

- Excisional biopsy was adequate $97 \%$ of the time, while CNB was adequate $58 \%$

- CNB found to have a diagnostic odds ratio of 0.03583

- Inadequate CNB samples were found regardless of needle size

- Most common CNB sites (axillary, inguinal, supraclavicular) are easily accessible for excision 


\section{Sidney Kimmel}

Medical College.

at Thomas Jefferson University

\section{Conclusions}

- Excisional biopsy should remain standard of care for initial diagnosis of lymphoma

- Use of CNB has been increasing at Jefferson from 19\% in 2016 to $31.6 \%$ in 2018

$-27.7 \%$ in 2019

- We would like to find a way to reduce these numbers 


\section{Sidney Kimmel}

Medical College.

at Thomas Jefferson University

\section{Future Directions}

- A Ql project is underway

- Goals:

- Understand the reasons for ordering CNB or excisional biopsy

- Educate the key providers involved

- Variables being considered:

- Was surgery involved? Oncology?

- Inpatient vs Outpatient

- Suspected diagnosis prior to biopsy 


\section{Acknowledgements}

- I would like to thank my team members George Ye, Catharine Tucker, and Christopher Gardner for their help in gathering, reviewing, and analyzing all of the data

- Special thanks to Dr. Adam Binder and Dr. Guldeep Uppal for their mentorship and leadership throughout the project 